\title{
Suppressive Effects of Puerariae Radix on the Breast Tumor Incidence in Rats Treated with DMBA
}

\author{
Chien-Hung Chen ${ }^{1}$, Szu-Hsien $\mathrm{Wu}^{2}$, Yang-Ming Tseng ${ }^{3}$, Jia-Bin Liao ${ }^{3}$, Hsiao-Ting Fu${ }^{3}$, Shih-Meng Tsai ${ }^{4}$ \\ \& Li-Yu Tsai ${ }^{1}$ \\ ${ }^{1}$ Department of Medical Laboratory Science and Biotechnology, Kaohsiung Medical University, Kaohsiung, \\ Taiwan \\ ${ }^{2}$ Division of plastic surgery, Department of Surgery, Taipei Veterans General Hospital and Yang Ming \\ University, Taipei, Taiwan \\ ${ }^{3}$ Department of Pathology and Laboratory Medicine, Kaohsiung Veterans General Hospital, Kaohsiung, Taiwan \\ ${ }^{4}$ Department of Public Health and Environmental Medicine, Faculty of Medicine, Kaohsiung Medical \\ University, Kaohsiung, Taiwan \\ Correspondence: Li-Yu Tsai, Department of Medical Laboratory Science and Biotechnology, Kaohsiung Medical \\ University, No. 100, Shih-Chuan 1st Road, Kaohsiung 807, Taiwan. Tel: 886-7-312-1101 ext. 2350. E-mail: \\ tsliyu@kmu.edu.tw \\ Shih-Meng Tsai, Department of Public Health and Environmental Medicine, Faculty of Medicine, Kaohsiung \\ Medical University, No. 100, Shih-Chuan 1st Road, Kaohsiung 807, Taiwan. Tel: 886-7-312-1101 ext. 2775. \\ E-mail: tsaism@kmu.edu.tw
}

Received: May 2, 2017 Accepted: May 30, $2017 \quad$ Online Published: June 15, 2017

doi:10.5539/jas.v9n7p68 URL: https://doi.org/10.5539/jas.v9n7p68

\begin{abstract}
Puerariae Radix (PR) is the root of Pueraria lobata, an herb widely used in traditional Chinese medicine and as a food seasoning. Owing to its potential anti-oxidative ability, the effects of PR on the inhibition of breast tumors were investigated in this study using the 7,12-dimethylbenz[a]anthracene (DMBA)-treated rat model. Thirty-two female Sprague-Dawley rats were randomly assigned to one of four different treatment groups, with or without PR and/or DMBA administration. At the age of 177 days, all rats were sacrificed, the number and size of tumors were recorded, and blood and tissue samples were collected for assessment of hematological parameters, redox status, and tumorigenesis-related factors. We found that PR supplementation decreased tumor incidence and WBC count but increased the IgM levels, and significantly altered the redox status, elevated serum TGF- $\beta$ levels, and reduced serum VEGF-C and ICAM-1 levels. The mechanism by which PR decreased the incidence of DMBA-induced rat breast tumors might include ameliorating immunity, enhancing the antioxidant status, increasing the hepatic excretion of carcinogenic metabolites of DMBA, and influencing the expression of tumorigenesis-related factors.
\end{abstract}

Keywords: Puerariae Radix, breast tumor, antioxidant system, 7,12-dimethylbenz[a]anthracene, Sprague-Dawley rats

\section{Introduction}

Globally, breast cancer is one of the most common types of malignant tumor. According to the latest statistical report from the National Cancer Institute, it was estimated that there would be 246,660 new cases of breast cancer among females and that an estimated 40,450 people would die of this disease in 2016 (NCI, 2016). There are two major approaches to preventing the occurrence of breast cancer: avoiding risk factors and increasing protective factors. Breast cancer risk factors can be distinguished from lifestyle-related factors and represent those not related to personal choice, such as genetic risks. Aside from changes in lifestyle-related factors, which may be a useful approach, the use of medication to reduce the risk of breast cancer represents another option. The two main drugs prescribed for this purpose are tamoxifen and raloxifene, although these drugs are associated with several side effects such as symptoms of menopause (LP, 2003; Company, 2007). Thus, there is increasing interest in the use of traditional Chinese medicine (including isoflavonoid-rich herbs) as a potential alternative for the prevention and treatment of breast cancer (Moselhy \& Al mslmani, 2008; Mafuvadze et al., 2011). 
Puerariae Radix (PR) is the root of Pueraria lobata, an herb widely used in traditional Chinese medicine and food preparation. It is commonly prescribed to relieve fever and dysentery, promote the production of body fluid, facilitate eruption, and lessen stiffness and pain in the nape (College, 1986). PR contains several isoflavonoids, including puerarin, daidzin, daidzein, and genistein (Chiang et al., 2005). Recent pharmacological research has demonstrated that puerarin, a major isoflavone glycoside of PR, exhibits a wide range of biological activities including protective effects in ischemic myocardial injury (Liu et al., 2014), inflammation (Jiang et al., 2016), and oxidation (Ma et al., 2014; Wang et al., 2016). In addition, previous studies have indicated that pretreatment with Pueraria mirifica (another species of Pueraria) decreases breast tumor incidence in vivo (Cherdshewasart et al., 2007), and that PR isoflavones and their metabolites inhibit growth and induce apoptosis in breast cancer cell lines (Lin et al., 2009). However, the mechanism behind the protective effects of PR against breast tumorigenesis in animal models remains unclear. Investigation of the in vivo effects of $P R$ is therefore warranted.

A previous study indicated that elevated oxidative status arising from the imbalance between reactive oxygen species (ROS) and antioxidant systems played an important role in carcinogenesis (Wu, 2006), a finding consistent with other studies that observed increased oxidative stress in patients with breast cancer (Yeh et al., $2005,2006)$. ROS are a family of molecules that include highly reactive free oxygen radicals produced in all cells during oxygen metabolism. ROS induce diverse biological responses according to the concentrations at which they are present (Sena \& Chandel, 2012). At low levels, ROS have been recognized as intracellular signal transduction molecules that regulate the post-translational modification of kinases and phosphatases to increase cell proliferation and survival (Lee et al., 2002; Giannoni et al., 2005). However, excessive ROS production can cause damage to cellular macromolecules such as DNA, proteins, and lipids (Valko et al., 2006). Cells therefore counteract aberrant ROS production by increasing antioxidant system expression, such as by elevating the glutathione (GSH) levels and antioxidant enzyme activities. In recent years, the antioxidant activities of PR have been demonstrated in various diseases including type 2 diabetes mellitus (Xie \& Du, 2011), chronic lead nephrotoxicity (Wang et al., 2013), and neurodegenerative disease (Zhu et al., 2015). However, the effects of PR on oxidative stress in breast tumors are yet to be fully elucidated.

Moreover, various tumorigenesis-related factors such as transforming growth factor beta (TGF- $\beta$ ), vascular endothelial growth factor-C (VEGF-C), and intracellular cell adhesion molecule-1 (ICAM-1) have been shown to participate in tumor growth and dissemination (Roskoski, 2007; Buijs et al., 2011; Kotteas et al., 2014). de Jong et al., have demonstrated that TGF- $\beta$ expression levels correlated with angiogenesis and prognosis of breast cancer patients (de Jong et al., 1998). The VEGF-C and the VEGF receptor 3 autocrine signaling pathway is known to regulate mammary tumor cell survival and proliferation (Varney \& Singh, 2015). Furthermore, higher serum levels of ICAM-1 were observed in patients with breast cancer and lymph node metastases (Rykala et al., 2011). However, little is known about the ability of PR to modulate these tumorigenesis-related factors.

Therefore, the purpose of this study was to evaluate the effects of PR in vivo on 7,12-dimethylbenz[a]anthracene (DMBA)-induced mammary tumors in Sprague-Dawley female rats. The use of DMBA to induce mammary tumors represents one of the most widely used models of rat mammary carcinogenesis and is appropriate for the study of mammary tumor initiation and promotion (Mehta, 2000). Furthermore, variations in oxidative status and the previously described tumorigenesis-related factors were explored after PR treatment.

\section{Materials and Methods}

\subsection{Materials}

All chemicals and reagents used in this study were of analytical grade. PR in powdered form was purchased from Sun Ten Pharmaceutical Co., Ltd. (Taiwan). Zoletil ${ }^{\mathbb{Q}}$ was obtained from Virbac Laboratories (Carros, France). DMBA, thiobarbituricacid (TBA), 1,1,3,3-tetraethoxypropane (TEP), metaphosphoric acid (MPA), sodium nitrite, sodium nitrate, GSH, and oxidized glutathione (GSSG) were obtained from Sigma (St. Louis, MO, USA). Boric acid was obtained from Mallinckrodt Baker, Inc. (Phillipsburg, NJ, USA). Superoxide dismutase (SOD), glutathione peroxidase (GPx), and glutathione reductase (GRx) activity was assayed using commercial assay kits (Randox Laboratories, UK). IgM, IgG, TGF- $\beta$, ICAM-1, and VEGF-C levels were assayed by enzyme-linked immunosorbent assay (ELISA; IgM and IgG, Immunology Consultants Laboratory, Newberg, OR, USA; TGF- $\beta$, Bender Medsystems, Vienna, Austria; and ICAM-1 and VEGF-C, R\&D Systems, Minneapolis, MN, USA). Primary antibodies against glutathione S-transferase pi (GST-pi), $\beta$-actin, and secondary antibodies (goat anti-rabbit and goat anti-mouse IgG) were obtained from Santa Cruz Biotechnology, Inc. (Santa Cruz, California, USA). 


\subsection{Animals and Experimental Design}

The study was approved by the Institutional Animal Care and Use Committee (IACUC) of Kaohsiung Medical University (approval no. 95152). All experiments were performed in accordance with relevant guidelines and regulations. Thirty-two female Sprague-Dawley rats (age: 45 days; weight: 194 $\pm 8 \mathrm{~g}$ ) purchased from BioLasco Co., Ltd. (Taiwan) and housed in stainless steel cages in a controlled environment of a $12 \mathrm{~h}$ light and $12 \mathrm{~h}$ dark cycle at $25 \pm 2{ }^{\circ} \mathrm{C}$. After 1 week of acclimatization, rats were randomly assigned to one of four groups $(\mathrm{n}=8$ per group): control group (no DMBA or PR treatment), $\mathrm{PR}^{+}$group (treated with $\mathrm{PR}$ only), $\mathrm{DMBA}^{+}$group (treated with DMBA only), and $\mathrm{DMBA}^{+} \mathrm{PR}^{+}$group (treated with both DMBA and PR). At the age of 52 days, the 16 rats in the $\mathrm{DMBA}^{+}$and $\mathrm{DMBA}^{+} \mathrm{PR}^{+}$groups were orally administered DMBA $(75 \mathrm{mg} / \mathrm{kg}$ body weight $)$ to induce the development of breast tumors while the $\mathrm{PR}^{+}$and the $\mathrm{DMBA}^{+} \mathrm{PR}^{+}$groups were supplemented with $\mathrm{PR}(1.75 \mathrm{~g} / \mathrm{kg}$ body weight, once per day). The number and size of tumors was recorded, and rats were weighed once per week. At the age of 177 days, all rats were sacrificed after anaesthetization with Zoletil ${ }^{\mathbb{R}}$ and blood, liver, and tumor samples were collected for further analysis. Further, to examine which types of tumor were induced by DMBA, sections of breast tissues from the rats were analyzed using hematoxylin and eosin (H\&E) staining.

\subsection{Sample Collection and Preparation}

Fasting blood samples were collected from the tail vein of each rat and aliquoted into two EDTA tubes. A complete blood count (CBC) (XE-2100, Sysmex) and GPx assay was performed on one sample, and plasma was obtained from the other sample by centrifugation and used for malondialdehyde (MDA), nitrite, nitrate, IgM, IgG, TGF- $\beta$, ICAM- 1 , and VEGF-C assays. Following the removal of plasma from the sample, the erythrocytes were washed three times with normal saline and aliquots of washed red blood cells (RBC) were assayed for GSH status, SOD, and GRx.

\subsection{Assay of MDA Levels}

Products of MDA in plasma were estimated by the TBA method (Yeh et al., 2005). MDA reacts with TBA under acidic conditions to form a complex with maximum absorbance at $532 \mathrm{~nm}$. Plasma samples $(150 \mu \mathrm{L})$ were mixed with $0.75 \mathrm{~mL}$ of $0.05 \mathrm{M} \mathrm{HCl}$ and $0.25 \mathrm{~mL}$ of $0.67 \% \mathrm{TBA}$, and then mixed and boiled in heated water at $95{ }^{\circ} \mathrm{C}$ for $30 \mathrm{~min}$. After cooling, products were extracted in $1 \mathrm{~mL}$ of $15 \%$ methanol in n-butanol and centrifuged at $2500 \mathrm{rpm}$ at $4{ }^{\circ} \mathrm{C}$ for $30 \mathrm{~min}$. The absorbance of the supernatant was determined at $532 \mathrm{~nm}$ by using a spectrophotometer (Spectronic $^{\circledR} 20$ Genesys $^{\mathrm{TM}}$, Thermo Fisher Scientific, Waltham, MA, USA).

\subsection{GSH and GSSG Assay}

GSH and GSSG were assayed according to the method of Yen et al., (Yeh et al., 2005). One hundred $\mu \mathrm{L}$ of washed RBC was added to $300 \mu \mathrm{L}$ of ice-cold 5\% metaphosphoric acid. To precipitate proteins completely, samples were vortexed and incubated on ice for $10 \mathrm{~min}$. After centrifugation at $12,000 \mathrm{rpm}$ for $10 \mathrm{~min}$ at $4{ }^{\circ} \mathrm{C}$, supernatants were filtered through a $0.2 \mu \mathrm{m}$ filter and diluted fivefold before being injected into a capillary electrophoresis system (P/ACE-MDQ, Beckman Coulter, Fullerton, USA). The analysis was performed at a constant temperature $\left(28{ }^{\circ} \mathrm{C}\right)$ using $300 \mathrm{mM}$ borate running buffer $(\mathrm{pH} 7.8)$ and with the UV absorbance detectors set to $200 \mathrm{~nm}$.

\subsection{Nitrite and Nitrate Assay}

Nitrite and nitrate were assayed according to the method of Yen et al., (Yeh et al., 2005). One hundred $\mu \mathrm{L}$ of plasma was added to $400 \mu \mathrm{L}$ distilled water and filtered through a $0.2 \mu \mathrm{m}$ filter before being injected into the capillary electrophoresis system (P/ACE-MDQ, Beckman Coulter). The analysis was performed at a constant temperature $\left(23^{\circ} \mathrm{C}\right)$ using $100 \mathrm{mM}$ borate running buffer $(\mathrm{pH} \mathrm{10.0)}$ ) and with the $\mathrm{UV}$ absorbance detectors set to $214 \mathrm{~nm}$. The total nitric oxide (NO) was represented by the sum of the nitrite and nitrate contents for further statistical analysis.

\subsection{Assay of SOD, GPx, and GRx Activity}

SOD, GPx, and GRx activity was measured using commercial assay kits (Ransod, Ransel, and GR kits, respectively) (Randox Laboratories, Antrim, UK). In brief, $25 \mu \mathrm{L}$ whole blood samples were used for the GPx assay, and $250 \mu \mathrm{L}$ and $500 \mu \mathrm{L}$ of packed cells were washed three times with physiologic saline for the SOD and GRx assays. All samples were assayed on an autoanalyzer (Synchron CX 7, Beckman Coulter). The results were expressed as $\mathrm{U} / \mathrm{g} \mathrm{Hb}$.

\subsection{IgM, IgG, TGF- $\beta$, ICAM-1, and VEGF-C Assays}

Serum IgM, IgG, TGF- $\beta$, ICAM-1, and VEGF-C levels were assessed by ELISA (Immunology Consultants Laboratory; Bender Medsystems, R\&D Systems) according to the manufacturer's instructions. 


\subsection{Western Blot Analysis for GST-pi in Liver and Tumor Tissues}

Tissues were homogenized using radioimmunoprecipitation (RIPA) lysis buffer ( $150 \mathrm{mM} \mathrm{NaCl}, 50 \mathrm{mM}$ Tris, $\mathrm{pH}$ $7.5,1 \%$ Tween $20,0.5 \%$ sodium deoxycholate, and $0.1 \%$ SDS) and centrifuged at $13,200 \mathrm{rpm}$ for $25 \mathrm{~min}$ at $4{ }^{\circ} \mathrm{C}$. Protein concentrations of the supernatants were measured using an autoanalyzer (Vitros 950 Ortho Clinical Diagnostics, Rochester, NY, USA). Samples with $50 \mu \mathrm{g}$ total protein were fractionated by $12 \%$ SDS-PAGE, transferred to a polyvinylidene difluoride membrane, and blocked with 5\% milk in Tris-buffered saline (TBS) for $1 \mathrm{~h}$. Next, the membrane was incubated for $1 \mathrm{~h}$ with a primary antibody (anti-GST-pi: 1:500; anti- $\beta$-actin: 1:5000) and probed for $1 \mathrm{~h}$ with horseradish peroxidase (HRP)-conjugated goat anti-rabbit IgG (for GST-pi) or HRP-conjugated goat anti-mouse IgG (for $\beta$-actin). Following extensive washed with TBS containing $0.05 \%$ (v/v) Tween 20, reactive bands were developed on film using an enhanced chemiluminescence kit (Millipore, Temecula, CA, USA). The band intensity was quantified by densitometry, and the results were expressed relative to the expression of the constitutively expressed protein $\beta$-actin.

\subsection{Statistical Analysis}

All data were presented as mean \pm SEM. Statistical analysis was performed by Student's $t$ test and one-way analysis of variance (ANOVA) with a least significant difference (LSD) post-test. P values less than 0.05 were considered statistically significant. All statistical analysis was performed using SPSS v17.0 software (IBM, Armonk, New York, USA).

\section{Results}

\subsection{Effects of PR on Body Weight and Tumorigenesis}

The histological examination of DMBA-induced breast lesions and normal breast tissues is shown in Figure 1 . All tumors were malignant, and the malignant breast carcinoma lesions were composed of large cells with hyperchromatic nuclei in a desmoplastic stroma. Regarding the effects of PR on body weight, significant decreases in body weight were observed in the $\mathrm{PR}^{+}$group and $\mathrm{DMBA}^{+} \mathrm{PR}^{+}$group compared with that in the control group $(\mathrm{p}<0.05)$. Furthermore, the percentage of tumor incidence was lower in the $\mathrm{DMBA}^{+} \mathrm{PR}^{+}$group $(37.5 \%)$ than in the $\mathrm{DMBA}^{+}$group $(100 \%)(\mathrm{p}=0.011)$. Although a trend of decreasing tumor multiplicity was observed in the $\mathrm{DMBA}^{+} \mathrm{PR}^{+}$group, the difference was not statistically significant (Table 1).
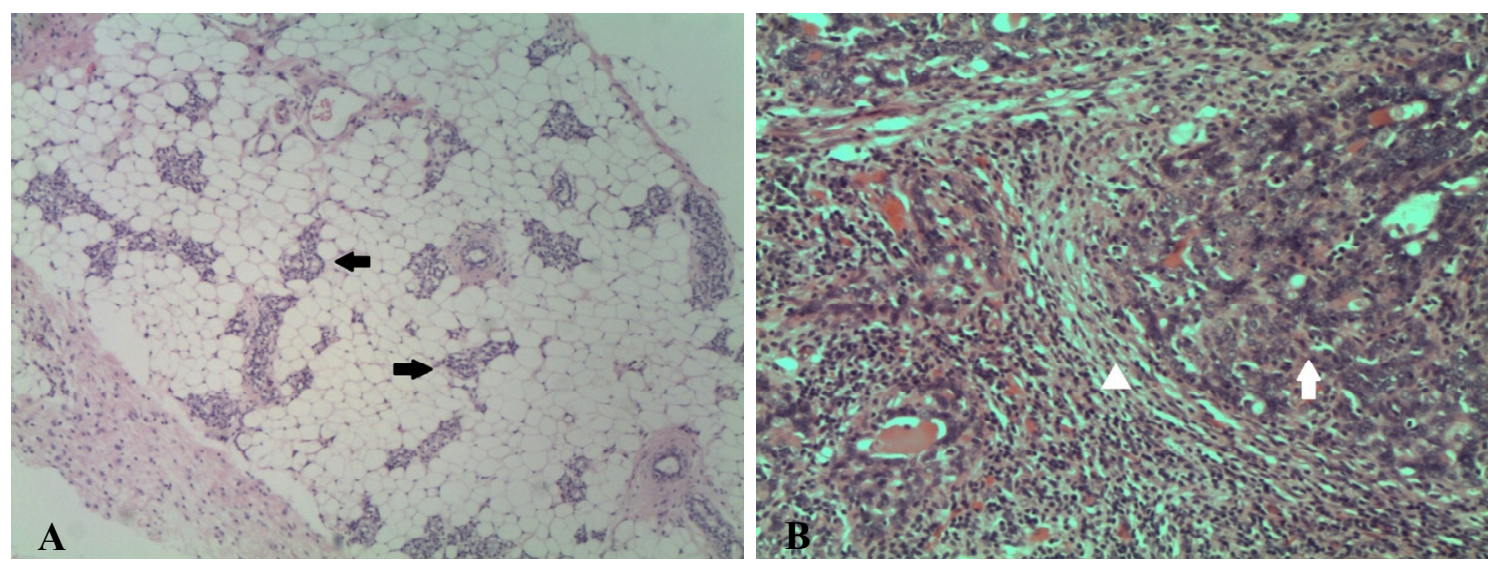

Figure 1. HE staining of normal and malignant breast tissue. The sections of breast tissues in the rats by hematoxylin-eosin (HE) staining. (A) Normal breast tissue, showing normal mammary glands (black arrows) in a fibroadipose stroma (40X); (B) Malignant lesion of invasive carcinoma, showing invasive adenocarcinoma (white arrow), consisting of neoplastic cells with large and hyperchromatic nuceli in a tubular and cribriform pattern with desmoplastic stroma (white arrow head) (400X) 
Table 1. General characteristics in the experimental rats ${ }^{\#}$

\begin{tabular}{lllll}
\hline Parameters & Control $(\mathrm{n}=8)$ & $\mathrm{PR}^{+}(\mathrm{n}=8)$ & $\mathrm{DMBA}^{+}(\mathrm{n}=8)$ & $\mathrm{DMBA}^{+} \mathrm{PR}^{+}(\mathrm{n}=8)$ \\
\hline Body weight $(\mathrm{g})$ & $321 \pm 8$ & $290 \pm 8^{\mathrm{a}}$ & $292 \pm 10^{\mathrm{a}}$ & $277 \pm 12$ \\
Incidence $(\%)$ & 0 & 0 & $100(8 / 8)$ & $37.5(3 / 8)^{\mathrm{b}}$ \\
Multiplicity & 0 & 0 & $2.8 \pm 0.7$ & $1.0 \pm 0.0$ \\
Average of Tumor Weight $(\mathrm{g}) /$ Tumor & 0 & 0 & $1.58 \pm 0.33$ & $3.90 \pm 3.15$ \\
Average Tumor Volume $\left(\mathrm{cm}^{3}\right) /$ Tumor & 0 & 0 & $3.18 \pm 0.73$ & $6.33 \pm 5.25$ \\
\hline
\end{tabular}

Note. ${ }^{\#}$ Data are expressed as mean \pm S.E.M.; ${ }^{a} \mathrm{p}<0.05$ compared with the control group; ${ }^{\mathrm{b}} \mathrm{p}<0.05$ compared with the $\mathrm{DMBA}^{+}$group.

\subsection{Effects of PR on Hematological Parameters}

As shown in Table 2, lymphocyte counts were significantly increased in the $\mathrm{PR}^{+}$and the $\mathrm{DMBA}^{+}$group $(\mathrm{p}<$ 0.05). In addition, white blood cell (WBC) and neutrophil counts were higher in the $\mathrm{DMBA}^{+}$group compared with the control group $(\mathrm{p}<0.05)$. However, $\mathrm{WBC}$ counts were significantly decreased in the $\mathrm{DMBA}^{+} \mathrm{PR}^{+}$group compared with the $\mathrm{DMBA}^{+}$group $(\mathrm{p}=0.015)$. Furthermore, the levels of $\mathrm{IgM}$ and $\operatorname{IgG}$ were significantly decreased in the $\mathrm{DMBA}^{+}$group and the $\mathrm{DMBA}^{+} \mathrm{PR}^{+}$group compared with the control group and the $\mathrm{PR}^{+}$group, respectively $(\mathrm{p}<0.05)$. In particular, higher levels of IgM were observed in the $\mathrm{DMBA}^{+} \mathrm{PR}^{+}$group than in the $\mathrm{DMBA}^{+}$group $(\mathrm{p}=0.043)$. No significant differences in the other factors evaluated were observed among the four groups.

Table 2. Effects of PR on the hematological parameters in the experimental rats ${ }^{\#}$

\begin{tabular}{lllll}
\hline Parameters & Control $(\mathrm{n})$ & $\mathrm{PR}^{+}(\mathrm{n})$ & $\mathrm{DMBA}^{+}(\mathrm{n})$ & $\mathrm{DMBA}^{+} \mathrm{PR}^{+}(\mathrm{n})$ \\
\hline $\mathrm{WBC}\left(10^{3} / \mu \mathrm{L}\right)$ & $2.99 \pm 0.48(7)$ & $4.06 \pm 0.32(6)$ & $5.50 \pm 0.43^{\mathrm{a}}(6)$ & $4.08 \pm 0.22^{\mathrm{b}}(7)$ \\
$\mathrm{RBC}\left(10^{6} / \mu \mathrm{L}\right)$ & $7.14 \pm 0.19(8)$ & $6.96 \pm 0.14(7)$ & $6.66 \pm 0.40(8)$ & $7.19 \pm 0.20(8)$ \\
$\mathrm{Hb}(\mathrm{g} / \mathrm{dL})$ & $13.6 \pm 0.4(8)$ & $13.0 \pm 0.3(7)$ & $13.5 \pm 0.3(7)$ & $13.7 \pm 0.3(8)$ \\
Platelet $\left(10^{3} / \mu \mathrm{L}\right)$ & $510 \pm 40(8)$ & $643 \pm 51(6)$ & $529 \pm 48(7)$ & $600 \pm 44(7)$ \\
Neutrophil $(\%)$ & $19.8 \pm 2.1(8)$ & $10.6 \pm 0.9(7)$ & $25.5 \pm 5.2(8)$ & $16.3 \pm 3.9(8)$ \\
Lymphocyte $(\%)$ & $74.2 \pm 3.1(8)$ & $85.9 \pm 1.4(7)$ & $69.1 \pm 5.9(8)$ & $77.5 \pm 4.4(8)$ \\
Monocyte $(\%)$ & $3.64 \pm 1.75(8)$ & $2.29 \pm 0.53(7)$ & $3.65 \pm 1.14(8)$ & $4.01 \pm 1.27(8)$ \\
Neutrophil $\left(10^{3} / \mu \mathrm{L}\right)$ & $0.48 \pm 0.11(8)$ & $0.47 \pm 0.04(7)$ & $1.62 \pm 0.48^{\mathrm{a}}(8)$ & $1.09 \pm 0.58(8)$ \\
Lymphocyte $\left(10^{3} / \mu \mathrm{L}\right)$ & $1.96 \pm 0.43(8)$ & $4.04 \pm 0.62^{\mathrm{a}}(7)$ & $4.21 \pm 0.91^{\mathrm{a}}(8)$ & $3.71 \pm 0.46(8)$ \\
Monocyte $\left(10^{3} / \mu \mathrm{L}\right)$ & $0.11 \pm 0.06(8)$ & $0.10 \pm 0.03(7)$ & $0.21 \pm 0.07(8)$ & $0.18 \pm 0.04(8)$ \\
IgM (mg/dL) & $26.7 \pm 3.4(7)$ & $25.2 \pm 2.4(8)$ & $11.1 \pm 1.4^{\mathrm{a}}(6)$ & $18.3 \pm 1.5^{\mathrm{b}, \mathrm{c}}(8)$ \\
IgG $(\mathrm{mg} / \mathrm{dL})$ & $1998 \pm 305(7)$ & $1966 \pm 210(6)$ & $1273 \pm 142^{\mathrm{a}}(7)$ & $1121 \pm 251^{\mathrm{c}}(7)$ \\
\hline
\end{tabular}

Note. ${ }^{\#}$ Data are expressed as mean \pm S.E.M.; The numbers in the parenthesis indicate the numbers of the study population; ${ }^{\mathrm{a}} \mathrm{p}<0.05$ compared with the control group; ${ }^{\mathrm{b}} \mathrm{p}<0.05$ compared with the $\mathrm{DMBA}^{+}$group; ${ }^{\mathrm{c}} \mathrm{p}<0.05$ compared with the $\mathrm{PR}^{+}$group.

\subsection{Effects of PR on Antioxidant Status}

As shown in Table 3, SOD activity and GSH/GSSG ratio in the blood, and GSH, GSSG, and T-GSH (total GSH) levels in liver tissue were significantly increased in the $\mathrm{PR}^{+}$group compared with the control group $(\mathrm{p}<0.05)$. Furthermore, SOD and GRx activity, GSH and T-GSH levels, GSH/GSSG blood ratio, and GSSG and T-GSH levels in liver tissue from the $\mathrm{DMBA}^{+}$group were higher than the corresponding values for the control group (p $<0.05$ ). Additionally, lower SOD and GRx activity, lower GSH/GSSG ratio, and higher GSSG levels were observed in blood from the $\mathrm{DMBA}^{+} \mathrm{PR}^{+}$group than from the $\mathrm{DMBA}^{+}$group $(\mathrm{p}<0.05)$. However, GSH and T-GSH levels and GSH/GSSG ratios were higher in liver tissues from the $\mathrm{DMBA}^{+} \mathrm{PR}^{+}$group compared with the $\mathrm{DMBA}^{+}$group $(\mathrm{p}<0.001)$. No significant difference in GSH status of breast tumor tissues was observed between the $\mathrm{DMBA}^{+} \mathrm{PR}^{+}$and $\mathrm{DMBA}^{+}$groups. 
Table 3. Effects of PR on the antioxidant statuses in the experimental rats ${ }^{\#}$

\begin{tabular}{|c|c|c|c|c|}
\hline Parameters & Control (n) & $\mathrm{PR}^{+}(\mathrm{n})$ & $\operatorname{DMBA}^{+}(\mathrm{n})$ & $\mathrm{DMBA}^{+} \mathrm{PR}^{+}(\mathrm{n})$ \\
\hline \multicolumn{5}{|l|}{ Blood } \\
\hline SOD (U/g Hb) & $1428 \pm 23(8)$ & $1627 \pm 55^{\mathrm{a}}(7)$ & $1567 \pm 47^{\mathrm{a}}(8)$ & $1400 \pm 26^{\mathrm{b}, \mathrm{c}}(8)$ \\
\hline GPx (U/g Hb) & $578 \pm 14(8)$ & $600 \pm 24(7)$ & $565 \pm 13(8)$ & $528 \pm 15^{\mathrm{b}}(8)$ \\
\hline GRx (U/g Hb) & $3.30 \pm 0.26(8)$ & $2.71 \pm 0.13(7)$ & $3.96 \pm 0.23^{\mathrm{a}}(8)$ & $3.03 \pm 0.17^{\mathrm{c}}(8)$ \\
\hline $\mathrm{GSH}(\mu \mathrm{M})$ & $742 \pm 15(6)$ & $799 \pm 64(4)$ & $930 \pm 42^{a}(7)$ & $913 \pm 56(7)$ \\
\hline GSSG $(\mu \mathrm{M})$ & $47.0 \pm 3.4(6)$ & $28.6 \pm 3.0(4)$ & $31.5 \pm 1.9(7)$ & $68.7 \pm 9.5^{\mathrm{b}, \mathrm{c}}(7)$ \\
\hline T-GSH $(\mu \mathrm{M})$ & $837 \pm 12(6)$ & $856 \pm 60(4)$ & $993 \pm 45^{\mathrm{a}}(7)$ & $1050 \pm 50^{\mathrm{b}}(7)$ \\
\hline GSH/GSSG & $16.3 \pm 1.5(6)$ & $29.5 \pm 5.3^{\mathrm{a}}$ (4) & $30.0 \pm 1.5^{\mathrm{a}}(7)$ & $15.4 \pm 2.8^{\mathrm{b}, \mathrm{c}}(7)$ \\
\hline \multicolumn{5}{|l|}{ Liver tissue } \\
\hline $\mathrm{GSH}(\mu \mathrm{M} / \mathrm{g})$ & $12.7 \pm 1.9(8)$ & $40.2 \pm 2.8^{\mathrm{a}}(8)$ & $17.7 \pm 2.4(8)$ & $50.4 \pm 2.4^{\mathrm{b}, \mathrm{c}}(8)$ \\
\hline GSSG $(\mu \mathrm{M} / \mathrm{g})$ & $2.3 \pm 0.2(8)$ & $6.6 \pm 0.5^{\mathrm{a}}(8)$ & $4.7 \pm 0.9^{\mathrm{a}}(8)$ & $3.9 \pm 0.2^{b}(8)$ \\
\hline T-GSH $(\mu \mathrm{M} / \mathrm{g})$ & $17.3 \pm 2.0(8)$ & $53.4 \pm 3.1^{\mathrm{a}}(8)$ & $27.2 \pm 3.5^{\mathrm{a}}(8)$ & $58.2 \pm 2.6^{\mathrm{c}}(8)$ \\
\hline GSH/GSSG & $5.6 \pm 0.8(8)$ & $6.3 \pm 0.7(8)$ & $4.3 \pm 0.8(8)$ & $13.0 \pm 0.5^{\mathrm{b}, \mathrm{c}}(8)$ \\
\hline Breast tissue & \multicolumn{2}{|c|}{ Normal breast tissue } & \multicolumn{2}{|c|}{ Breast tumor tissue } \\
\hline $\mathrm{GSH}(\mu \mathrm{M} / \mathrm{g})$ & N.D. & N.D. & $16.3 \pm 3.0(8)$ & $15.1 \pm 7.9$ \\
\hline GSSG $(\mu \mathrm{M} / \mathrm{g})$ & N.D. & N.D. & $1.6 \pm 0.5(8)$ & $1.0 \pm 0.5(3)$ \\
\hline T-GSH $(\mu \mathrm{M} / \mathrm{g})$ & N.D. & N.D. & $19.4 \pm 3.8(8)$ & $17.0 \pm 8.8$ \\
\hline GSH/GSSG & N.D. & N.D. & $15.1 \pm 3.1(8)$ & $16.3 \pm 2.2(3)$ \\
\hline
\end{tabular}

Note. ${ }^{\#}$ Data are expressed as mean \pm S.E.M.; The numbers in the parenthesis indicate the numbers of the study population; ${ }^{a} \mathrm{p}<0.05$ compared with the control group; ${ }^{\mathrm{b}} \mathrm{p}<0.05$ compared with the $\mathrm{PR}^{+}$group; ${ }^{\mathrm{c}} \mathrm{p}<0.05$ compared with the $\mathrm{DMBA}^{+}$group.

\subsection{Effects of PR on Oxidative Stress and Tumorigenesis-Related Factors}

Nitrite levels were significantly decreased in the $\mathrm{DMBA}^{+} \mathrm{PR}^{+}$group compared with the $\mathrm{DMBA}^{+}$group $(\mathrm{p}=0.04)$. Similar results were observed for total NO, although the $\mathrm{p}$ value was borderline significant $(0.058)$. However, no significant differences in other oxidative stress-related factors were observed among the four groups (Table 4). For the evaluation of tumorigenesis-related factors, higher levels of VEGF-C were observed in the DMBA group than in the control group $(\mathrm{p}<0.001)$. However, the levels of VEGF-C were significantly decreased in the $\mathrm{DMBA}^{+} \mathrm{PR}^{+}$group compared with the DMBA ${ }^{+}$group $(\mathrm{p}<0.001)$. Higher levels of TGF- $\beta$ were observed in the $\mathrm{PR}^{+}$group compared with the control group $(\mathrm{p}=0.021)$, and TGF- $\beta$ and ICAM-1 levels in the DMBA $\mathrm{PR}^{+}$ group were significantly increased and decreased respectively, compared with the $\mathrm{DMBA}^{+}$group $(\mathrm{p}<0.05)$.

Table 4. Effects of PR on the oxidative stress and tumorigenesis-related factors in the experimental rats ${ }^{\#}$

\begin{tabular}{|c|c|c|c|c|}
\hline Parameters & Control (n) & $\mathrm{PR}^{+}(\mathrm{n})$ & $\mathrm{DMBA}^{+}(\mathrm{n})$ & $\operatorname{DMBA}^{+} \mathrm{PR}^{+}(\mathrm{n})$ \\
\hline \multicolumn{5}{|l|}{ Oxidative stress } \\
\hline $\operatorname{MDA}(\mu \mathrm{M})$ & $3.13 \pm 0.33(6)$ & $3.29 \pm 0.23(7)$ & $3.02 \pm 0.30(7)$ & $3.72 \pm 0.49(7)$ \\
\hline Nitrite $(\mu \mathrm{M})$ & $16.1 \pm 1.5(7)$ & $11.6 \pm 1.1(6)$ & $13.2 \pm 1.8(8)$ & $9.0 \pm 1.0^{\mathrm{c}}(8)$ \\
\hline Nitrate $(\mu \mathrm{M})$ & $21.6 \pm 2.4(7)$ & $18.2 \pm 2.7(6)$ & $21.0 \pm 3.7(8)$ & $17.5 \pm 1.7(8)$ \\
\hline Total NO $(\mu \mathrm{M})$ & $37.7 \pm 2.7(7)$ & $29.8 \pm 2.6(6)$ & $34.3 \pm 3.8(8)$ & $26.5 \pm 2.0(8)$ \\
\hline \multicolumn{5}{|c|}{ Tumorigenesis-related factors } \\
\hline TGF- $\beta(\mathrm{ng} / \mathrm{mL})$ & $34.7 \pm 2.2(6)$ & $55.1 \pm 6.5^{\mathrm{a}}(6)$ & $45.2 \pm 4.0(7)$ & $74.2 \pm 8.5^{\mathrm{b}, \mathrm{c}}(6)$ \\
\hline VEGF-C (ng/mL) & $131 \pm 31(6)$ & $200 \pm 20(5)$ & $380 \pm 34^{\mathrm{a}}(7)$ & $147 \pm 11^{\mathrm{c}}(5)$ \\
\hline ICAM-1 (ng/mL) & $12.6 \pm 2.2(8)$ & $7.6 \pm 1.3(7)$ & $14.9 \pm 1.5(8)$ & $9.5 \pm 1.7^{\mathrm{c}}(8)$ \\
\hline
\end{tabular}

Note. ${ }^{\#}$ Data are expressed as mean \pm S.E.M.; The numbers in the parenthesis indicate the numbers of the study population; ${ }^{a} \mathrm{p}<0.05$ compared with the control group; ${ }^{\mathrm{b}} \mathrm{p}<0.05$ compared with the $\mathrm{PR}^{+}$group; ${ }^{\mathrm{c}} \mathrm{p}<0.05$ compared with the $\mathrm{DMBA}^{+}$group. 


\subsection{Effects of PR on Relative GST-pi Protein Expression}

The effects of PR on relative GST-pi protein expression were examined by western blot analysis. As shown in Figure 2A, there was no significant difference in liver GST-pi protein expression between the control group and the $\mathrm{PR}^{+}$group. However, GST-pi protein expression significantly decreased in the $\mathrm{DMBA}^{+}$group compared with that in the control group $(\mathrm{p}=0.004)$. Moreover, liver GST-pi protein expression was higher in the $\mathrm{DMBA}^{+} \mathrm{PR}^{+}$ group than in the $\mathrm{DMBA}^{+}$group $(\mathrm{p}<0.001)$. However, in breast tumor tissue, GST-pi protein expression was not significantly different in the $\mathrm{DMBA}^{+} \mathrm{PR}^{+}$group compared with the $\mathrm{DMBA}^{+}$group (Figure $2 \mathrm{~B}$ ).

A

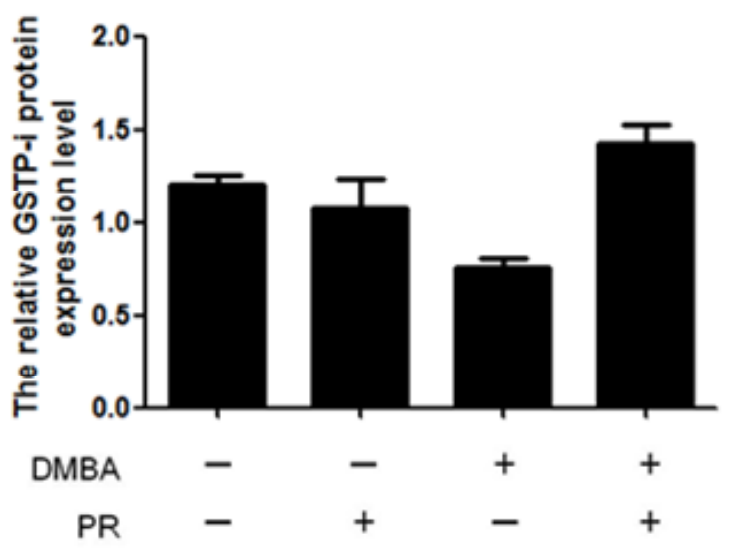

B

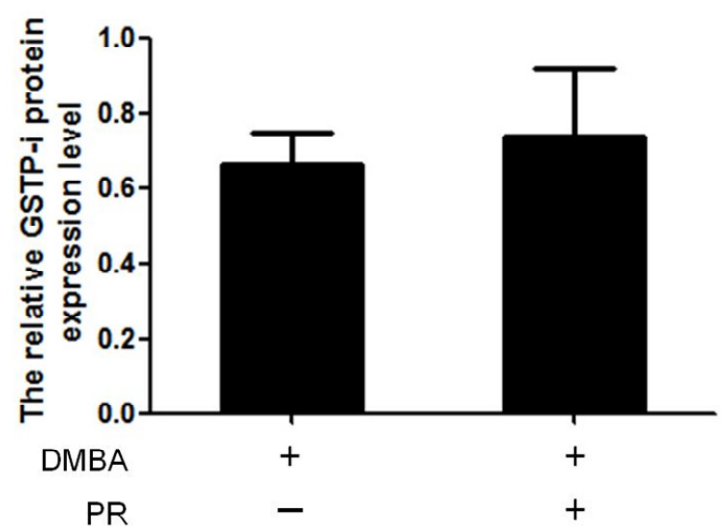

Figure 2. Effects of PR on the relative GST-pi protein expression in the liver tissue (A) and breast tumor tissue (B) of the experimental rats

Note. The relative GST-pi protein expression levels were determined by GST-pi/ $\beta$-actin. PR, Puerariae Radix. ${ }^{a} \mathrm{p}$ $<0.01$ compared with the control group. ${ }^{\mathrm{b}} \mathrm{p}<0.01$ compared with the $\mathrm{DMBA}^{+}$group.

\section{Discussion}

Several recent studies have indicated that traditional herbal medicine has significant effects in cancer treatment as well as prevention (Mafuvadze et al., 2011), although the detailed mechanism for these effects remains unknown. Although PR isoflavones and their metabolites have previously been shown to modulate the growth of breast cancer in vitro (Lin et al., 2009), this is the first study to investigate these effects in vivo to the best of our knowledge. The present study showed that the incidence of breast tumors decreased significantly following PR administration in a DMBA-induced breast tumor model. Although the average tumor weight and volume in DMBA rats supplemented with PR were higher than those in rats that did not receive PR, this was attributed to a particularly large tumor outlier in one DMBA rat that received PR. Interestingly, our data also showed that supplementation with PR effectively suppressed body weight gain in rats treated with or without DMBA, which was in agreement with a previous finding that puerarin, the major active component of PR, effectively inhibited body weight gain in rats chronically fed a high-fat diet by improving glucose and insulin intolerance (Zhang et al., 2010). These results strongly suggest that the potential mechanism behind the anticancer effects of PR might include decreasing obesity, an important risk factor for breast cancer, to reduce the risk of breast cancer formation.

According to Liu et al. and Ma et al., PR promotes immunity by increasing B-cell antibody production, lymphocyte transformation, and phagocytic rate, for example (Ma et al., 2002; Yunbo et al., 2002). PR intervention decreased the elevated WBC levels caused by DMBA treatment, an effect that could be explained by the anti-inflammatory activity of PR. Moreover, levels of IgM and IgG were remarkably decreased in DMBA rats compared with control rats, regardless of whether PR was administered or not, although PR treatment elevated IgM levels that were lowered following DMBA treatment. These findings indicate that PR reduced the incidence of breast tumors by increasing antibodies to ameliorate immunity in DMBA rats.

DMBA, a polycyclic aromatic hydrocarbon, requires metabolic activation to trigger its carcinogenicity (Barros et al., 2004). Among the metabolites of DMBA, trans-3,4-dihydrodiol-1,2-epoxide is a carcinogenic product that 
can damage DNA (Wong et al., 1983). As the process of metabolism is often accompanied by the formation of free radicals (Moselhy \& Al mslmani, 2008), the antioxidant system curbs the damaging effects caused by increased ROS. Regarding the antioxidant status of blood, Ray et al., observed that SOD activity was significantly elevated in breast cancer patients (Ray et al., 2000). Our previous study also showed that there were remarkably higher SOD and GRx activities in the blood of breast cancer patients (Yeh et al., 2005). Moreover, Navarro et al. reported that SOD and GRx activities were increased in the blood of tumor-bearing mice compared with non-tumor-bearing controls (Navarro et al., 1999). In the present study, higher SOD and GRx activities were observed in DMBA rats, although this finding was contrary to that of some previous studies (Pandi et al., 2010; Nandakumar \& Balasubramanian, 2012). The discrepancy between SOD and GRx activities in DMBA rats in this study and the previously published studies (Pandi et al., 2010; Nandakumar \& Balasubramanian, 2012) which can explain the activation of gene expression by oxidants through antioxidant responsive elements (AREs) (Rushmore et al., 1991).

The GSH system comprises GSH, GSSG, and the related enzymes GPx and GRx, which function together to decompose hydrogen peroxide $\left(\mathrm{H}_{2} \mathrm{O}_{2}\right)$ and other organic hydroperoxides (Chiou et al., 2014). GPx reduces $\mathrm{H}_{2} \mathrm{O}_{2}$ while oxidizing GSH, and GSSG is reduced back to GSH by GRx in the presence of NADPH (Yao et al., 2006). In this study, GSH levels and GSH/GSSG ratio in DMBA rats were higher than those in controls, which might be explained by the higher GRx activities observed in the DMBA group. Thus, in the DMBA rats treated with PR, because of the less harmful environment caused by PR, the relatively lower SOD and GRx activity led to the lower GSH/GSSG ratio and higher GSSG levels. The rat hepatic GSH statuses observed in this study also suggest that PR exerts antioxidant effects, regardless of whether DMBA was administered. These results were consistent with those from previous studies indicating that PR supplementation significantly increased hepatic GSH levels in ethanol-treated rats (Lee, 2004), lead-treated rats (Liu et al., 2011), and DMBA-treated hamsters (Rajasekaran et al., 2015). Likewise, the phase II detoxification enzyme, GST-pi, was suggested to facilitate the excretion of carcinogenic metabolites in conjugation with GSH. The hepatic GST-pi protein levels of DMBA rats were remarkably decreased in this study and indicated that the excretion of DMBA metabolites was impaired, thus leading to neoplasia as proposed in a previous study (Rajasekaran et al., 2015). Reduced hepatic GST-pi protein levels were observed in DMBA rats that received PR treatment, which suggested that PR reduced tumorigenesis by elevating the expression of GST-pi protein to increase the excretion of carcinogenic metabolites of DMBA in the liver. However, PR did not affect the GSH status or GST-pi protein levels in breast tumor tissue from DMBA rats. Regarding oxidative stress in groups, our data showed that lower levels of nitrite and total NO were observed in DMBA rats treated with PR compared with untreated DMBA rats, which may partly explain the effects of PR on free radical scavenging activities.

The overexpression of certain tumorigenesis-related factors such as VEGF-C, ICAM- 1 and TGF- $\beta$ has been observed in numerous tumors, indicating that these factors may play important roles in tumor initiation, growth, and development (Roskoski, 2007; Buijs et al., 2011; Kotteas et al., 2014). VEGF-C regulates angiogenesis, an indispensable mechanism in living organisms that controls proliferation, development, and reproduction in normal tissue as well as cancer tissue. In the present study, PR significantly reduced the elevated levels of VEGF-C in DMBA rats, suggesting that it might inhibit breast tumor formation by downregulating vascular angiogenesis factors in rat DMBA-induced breast tumors. An association between puerarin and VEGF has been reported in several studies, and puerarin has been suggested to suppress the vascularization of ectopic endometrial tissues stimulated by 17ß-estradiol (Wang et al., 2011) and to inhibit VEGF expression in retinas of streptozotocin-induced early diabetic rats (Chen et al., 2012a). Other reports suggest that puerarin may induce therapeutic angiogenesis by increasing VEGF mRNA expression in rats with myocardial infarction (Zhang et al., 2006). The discrepant effects of PR on VEGF expression may possibly be due to differences in species and disease types. Interestingly, similar results were shown with respect to the effect of PR on ICAM-1 levels. ICAM-1 is a multi-functional transmembrane protein, well known for its importance in stabilizing cell-cell interactions, proliferation, and adhesion (Kotteas et al., 2014). Previous studies have indicated that the inhibitory effects of puerarin on ICAM-1 expression were found to not only exist in human umbilical vein endothelial cells (Hu et al., 2010), but also to limit early-stage renal damage in diabetic rats (Pan et al., 2015). The present study showed that PR decreased the levels of ICAM-1 in DMBA-induced breast tumors in rats, an observation supported by the studies described previously. The effect of PR on TGF- $\beta$ levels was also investigated in this study. TGF- $\beta$ production has been linked to numerous disease states (Blobe et al., 2000). Our data showed that the levels of TGF- $\beta$ in rats that received PR treatment were significantly increased compared with rats that received no PR treatment, whether control rats or rats treated only with DMBA. However, several reports have indicated that puerarin suppressed TGF- $\beta$ expression in diabetic rats (She et al., 2014), mice with myocardial fibrosis (Chen et al., 2012b), and rats with hepatic fibrosis (Li et al., 2013). The TGF- $\beta$ pathway has a dual role 
in both tumor suppression and tumor promotion (Sheen et al., 2013). Zarzynska reported that in the early stages of breast cancer, TGF- $\beta$ inhibited epithelial cell cycle progression and promoted apoptosis to suppress tumorigenesis (Zarzynska, 2014). Therefore, we suggest that PR might suppress tumorigenesis in DMBA-induced breast tumor rats by increasing TGF- $\beta$ expression.

\section{Conclusions}

Taken together, PR supplementation not only promotes immunity, but also decreases the incidence of breast tumors and tumor multiplicity in the DMBA breast cancer rat model. Moreover, PR enhanced the antioxidant status of the DMBA rats by elevating hepatic GSH levels, and reduced tumorigenesis by increasing the excretion of carcinogenic metabolites of DMBA in the liver. The underlying mechanisms behind the inhibitory effects of $\mathrm{PR}$ on tumorigenesis may therefore involve the elevation of TGF- $\beta$ levels and reduction of VEGF-C and ICAM-1 levels, which has been summarized in Figure 3.

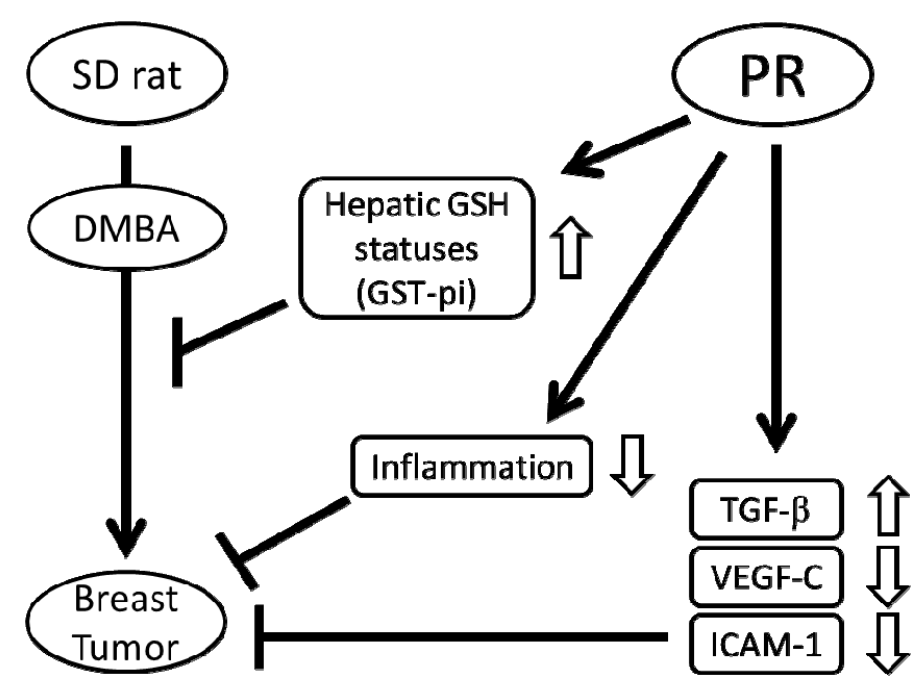

Figure 3. A proposed mechanism for the suppressive effects of PR on the tumorigenesis in the DMBA-induced rats. PR suppressed DMBA-induced tumorigenesis in the rats through the elevated hepatic GSH statuses (including GST-pi protein expression) and the TGF- $\beta$ levels; reducing the inflammation, VEGF-C and ICAM-1 levels

\section{Acknowledgements}

This work was supported by grant NSC 96-2320-B-037-012-MY3 from the Ministry of Science and Technology, Taiwan.

\section{References}

Barros, A. C., Muranaka, E. N., Mori, L. J., Pelizon, C. H., Iriya, K., Giocondo, G., \& Pinotti, J. A. (2004). Induction of experimental mammary carcinogenesis in rats with 7,12-dimethylbenz(a)anthracene. Rev Hosp Clin Fac Med Sao Paulo, 59(5), 257-261. https://doi.org/10.1590/S0041-87812004000500006

Blobe, G. C., Schiemann, W. P., \& Lodish, H. F. (2000). Role of transforming growth factor beta in human disease. N Engl J Med, 342(18), 1350-1358. https://doi.org/10.1056/NEJM200005043421807

Buijs, J. T., Stayrook, K. R., \& Guise, T. A. (2011). TGF-beta in the Bone Microenvironment: Role in Breast Cancer Metastases. Cancer Microenviron, 4(3), 261-281. https://doi.org/10.1007/s12307-011-0075-6

Chen, F., Zhang, H. Q., Zhu, J., Liu, K. Y., Cheng, H., Li, G. L., ... Xie, Z. G. (2012a). Puerarin enhances superoxide dismutase activity and inhibits RAGE and VEGF expression in retinas of STZ-induced early diabetic rats. Asian Pac J Trop Med, 5(11), 891-896. https://doi.org/10.1016/S1995-7645(12)60166-7

Chen, R., Xue, J., \& Xie, M. (2012b). Puerarin prevents isoprenaline-induced myocardial fibrosis in mice by reduction of myocardial TGF-betal expression. J Nutr Biochem, 23(9), 1080-1085. https://doi.org/10.1016/ j.jnutbio.2011.05.015 
Cherdshewasart, W., Panriansaen, R., \& Picha, P. (2007). Pretreatment with phytoestrogen-rich plant decreases breast tumor incidence and exhibits lower profile of mammary ERalpha and ERbeta. Maturitas, 58(2), 174-181. https://doi.org/10.1016/j.maturitas.2007.08.001

Chiang, H. M., Fang, S. H., Wen, K. C., Hsiu, S. L., Tsai, S. Y., Hou, Y. C., ... Chao, P. D. (2005). Life-threatening interaction between the root extract of Pueraria lobata and methotrexate in rats. Toxicol Appl Pharmacol, 209(3), 263-268. https://doi.org/10.1016/j.taap.2005.04.015

Chiou, S. S., Tsao, C. J., Tsai, S. M., Wu, Y. R., Liao, Y. M., Lin, P. C., \& Tsai, L. Y. (2014). Metabolic pathways related to oxidative stress in patients with hemoglobin h disease and iron overload. J Clin Lab Anal, 28(4), 261-268. https://doi.org/10.1002/jcla.21676

College, J. N. M. (1986). Dictionary of Chinese Traditional Medicine (pp. 2307-2310). Shanghai People's Publishing House, P.R. China.

Company, E. L. A. (2007). Medication Guide of EVISTA ${ }^{\circledR}$ (E-VISS-tah) Eli Lilly and Company.

de Jong, J. S., van Diest, P. J., van der Valk, P., \& Baak, J. P. (1998). Expression of growth factors, growth-inhibiting factors, and their receptors in invasive breast cancer. II: Correlations with proliferation and angiogenesis. J Pathol, 184(1), 53-57. https://doi.org/10.1002/(SICI)1096-9896(199801)184:1<53:: AID-PATH6>3.0.CO;2-7

Giannoni, E., Buricchi, F., Raugei, G., Ramponi, G., \& Chiarugi, P. (2005). Intracellular reactive oxygen species activate Src tyrosine kinase during cell adhesion and anchorage-dependent cell growth. Mol Cell Biol, 25(15), 6391-6403. https://doi.org/10.1128/MCB.25.15.6391-6403.2005

Hu, W., Zhang, Q., Yang, X., Wang, Y., \& Sun, L. (2010). Puerarin inhibits adhesion molecule expression in tnf-alpha-stimulated human endothelial cells via modulation of the nuclear factor kappa B pathway. Pharmacology, 85(1), 27-35. https://doi.org/10.1159/000264938

Jiang, M., Yun, Q., Niu, G., Gao, Y., Shi, F., \& Yu, S. (2016). Puerarin prevents inflammation and apoptosis in the neurocytes of a murine Parkinson's disease model. Genet Mol Res, 15(4). https://doi.org/10.4238/ gmr. 15047501

Kotteas, E. A., Boulas, P., Gkiozos, I., Tsagkouli, S., Tsoukalas, G., \& Syrigos, K. N. (2014). The intercellular cell adhesion molecule-1 (icam-1) in lung cancer: implications for disease progression and prognosis. Anticancer Res, 34(9), 4665-4672.

Lee, J. S. (2004). Supplementation of Pueraria radix water extract on changes of antioxidant enzymes and lipid profile in ethanol-treated rats. Clin Chim Acta, 347(1-2), 121-128. https://doi.org/10.1016/j.cccn.2004. 04.002

Lee, S. R., Yang, K. S., Kwon, J., Lee, C., Jeong, W., \& Rhee, S. G. (2002). Reversible inactivation of the tumor suppressor PTEN by $\mathrm{H}_{2} \mathrm{O}_{2}$. J Biol Chem, 277(23), 20336-20342. https://doi.org/10.1074/jbc.M111899200

Li, R., Xu, L., Liang, T., Li, Y., Zhang, S., \& Duan, X. (2013). Puerarin mediates hepatoprotection against CCl4-induced hepatic fibrosis rats through attenuation of inflammation response and amelioration of metabolic function. Food Chem Toxicol, 52, 69-75. https://doi.org/10.1016/j.fct.2012.10.059

Lin, Y. J., Hou, Y. C., Lin, C. H., Hsu, Y. A., Sheu, J. J., Lai, C. H., ... Tsai, F. J. (2009). Puerariae radix isoflavones and their metabolites inhibit growth and induce apoptosis in breast cancer cells. Biochem Biophys Res Commun, 378(4), 683-688. https://doi.org/10.1016/j.bbrc.2008.10.178

Liu, C. M., Ma, J. Q., \& Sun, Y. Z. (2011). Protective role of puerarin on lead-induced alterations of the hepatic glutathione antioxidant system and hyperlipidemia in rats. Food Chem Toxicol, 49(12), 3119-3127. https://doi.org/10.1016/j.fct.2011.09.007

Liu, S., Yu, S., Xu, C., Peng, L., Xu, H., Zhang, C., ... Liang, S. (2014). Puerarin alleviates aggravated sympathoexcitatory response induced by myocardial ischemia via regulating $\mathrm{P} 2 \mathrm{X} 3$ receptor in rat superior cervical ganglia. Neurochem Int, 70, 39-49. https://doi.org/10.1016/j.neuint.2014.03.004

LP, A. P. (2003). Medication Guide of NOLVADEX® (NOLE-vah-dex) Tablets AstraZeneca Pharmaceuticals LP.

Ma, J., Cheng, G., Li, D., \& Liu, H. (2002). The effects of Radix Puerariae decoction on levels of antibody and interleukin-2 in mice. Zhong Yao Cai, 25(10), 731-732. 
Ma, J. Q., Ding, J., Xiao, Z. H., \& Liu, C. M. (2014). Puerarin ameliorates carbon tetrachloride-induced oxidative DNA damage and inflammation in mouse kidney through ERK/Nrf2/ARE pathway. Food Chem. Toxicol., 71, 264-271. https://doi.org/10.1016/j.fct.2014.06.017

Mafuvadze, B., Benakanakere, I., Lopez Perez, F. R., Besch-Williford, C., Ellersieck, M. R., \& Hyder, S. M. (2011). Apigenin prevents development of medroxyprogesterone acetate-accelerated 7,12-dimethylbenz(a)anthracene-induced mammary tumors in Sprague-Dawley rats. Cancer Prev Res (Phila), 4(8), 1316-1324. https://doi.org/10.1158/1940-6207.CAPR-10-0382

Mehta, R. G. (2000). Experimental basis for the prevention of breast cancer. Eur J Cancer, 36(10), 1275-1282. https://doi.org/10.1016/S0959-8049(00)00100-3

Moselhy, S. S., \& Al mslmani, M. A. (2008). Chemopreventive effect of lycopene alone or with melatonin against the genesis of oxidative stress and mammary tumors induced by 7,12 dimethyl(a)benzanthracene in sprague dawely female rats. Mol Cell Biochem, 319(1-2), 175-180. https://doi.org/10.1007/s11010-008$9890-6$

Nandakumar, N., \& Balasubramanian, M. P. (2012). Hesperidin a citrus bioflavonoid modulates hepatic biotransformation enzymes and enhances intrinsic antioxidants in experimental breast cancer rats challenged with 7, 12-dimethylbenz (a) anthracene. J Exp Ther Oncol, 9(4), 321-335.

Navarro, J., Obrador, E., Carretero, J., Petschen, I., Avino, J., Perez, P., \& Estrela, J. M. (1999). Changes in glutathione status and the antioxidant system in blood and in cancer cells associate with tumour growth in vivo. Free Radic Biol Med, 26(3-4), 410-418. https://doi.org/10.1016/S0891-5849(98)00213-5

NCI. (2016). SEER Cancer Statistics Factsheets: Breast Cancer. National Cancer Institute. Bethesda, MD.

Pan, X., Wang, J., Pu, Y., Yao, J., \& Wang, H. (2015). Effect of Puerarin on Expression of ICAM-1 and TNF-alpha in Kidneys of Diabetic Rats. Med Sci Monit, 21, 2134-2140. https://doi.org/10.12659/ MSM.893714

Pandi, M., Manikandan, R., \& Muthumary, J. (2010). Anticancer activity of fungal taxol derived from Botryodiplodia theobromae Pat., an endophytic fungus, against 7, 12 dimethyl benz(a)anthracene (DMBA)-induced mammary gland carcinogenesis in Sprague Dawley rats. Biomed Pharmacother, 64(1), 48-53. https://doi.org/10.1016/j.biopha.2009.03.001

Rajasekaran, D., Manoharan, S., Prabhakar, M. M., \& Manimaran, A. (2015). Enicostemma littorale prevents tumor formation in 7,12-dimethylbenz(a)anthracene-induced hamster buccal pouch carcinogenesis. Hum Exp Toxicol, 34(9), 911-921. https://doi.org/10.1177/0960327114562033

Ray, G., Batra, S., Shukla, N. K., Deo, S., Raina, V., Ashok, S., \& Husain, S. A. (2000). Lipid peroxidation, free radical production and antioxidant status in breast cancer. Breast Cancer Res Treat, 59(2), 163-170. https://doi.org/10.1023/A:1006357330486

Roskoski, R. Jr. (2007). Vascular endothelial growth factor (VEGF) signaling in tumor progression. Crit Rev Oncol Hematol, 62(3), 179-213. https://doi.org/10.1016/j.critrevonc.2007.01.006

Rushmore, T. H., Morton, M. R., \& Pickett, C. B. (1991). The antioxidant responsive element. Activation by oxidative stress and identification of the DNA consensus sequence required for functional activity. $J$ Biol Chem, 266(18), 11632-11639.

Rykala, J., Przybylowska, K., Majsterek, I., Pasz-Walczak, G., Sygut, A., Dziki, A., \& Kruk-Jeromin, J. (2011). Angiogenesis markers quantification in breast cancer and their correlation with clinicopathological prognostic variables. Pathol Oncol Res, 17(4), 809-817. https://doi.org/10.1007/s12253-011-9387-6

Sena, L. A., \& Chandel, N. S. (2012). Physiological roles of mitochondrial reactive oxygen species. Mol Cell, 48(2), 158-167. https://doi.org/10.1016/j.molcel.2012.09.025

She, S., Liu, W., Li, T., \& Hong, Y. (2014). Effects of puerarin in STZ-induced diabetic rats by oxidative stress and the TGF-beta1/Smad2 pathway. Food Funct, 5(5), 944-950. https://doi.org/10.1039/c3fo60565e

Sheen, Y. Y., Kim, M. J., Park, S. A., Park, S. Y., \& Nam, J. S. (2013). Targeting the Transforming Growth Factor-beta Signaling in Cancer Therapy. Biomol Ther (Seoul), 21(5), 323-331. https://doi.org/10.4062/ biomolther.2013.072

Valko, M., Rhodes, C. J., Moncol, J., Izakovic, M., \& Mazur, M. (2006). Free radicals, metals and antioxidants in oxidative stress-induced cancer. Chem Biol Interact, 160(1), 1-40. https://doi.org/10.1016/j.cbi.2005. 12.009 
Varney, M. L., \& Singh, R. K. (2015). VEGF-C-VEGFR3/Flt4 axis regulates mammary tumor growth and metastasis in an autocrine manner. Am J Cancer Res, 5(2), 616-628.

Wang, C., Wang, W., Jin, X., Shen, J., Hu, W., \& Jiang, T. (2016). Puerarin attenuates inflammation and oxidation in mice with collagen antibody-induced arthritis via TLR4/NF-kappaB signaling. Mol Med Rep, 14(2), 1365-1370. https://doi.org/10.3892/mmr.2016.5357

Wang, D., Liu, Y., Han, J., Zai, D., Ji, M., Cheng, W., ... Yu, C. (2011). Puerarin suppresses invasion and vascularization of endometriosis tissue stimulated by 17beta-estradiol. PLoS One, 6(9), e25011. https://doi.org/10.1371/journal.pone.0025011

Wang, L., Lin, S., Li, Z., Yang, D., \& Wang, Z. (2013). Protective effects of puerarin on experimental chronic lead nephrotoxicity in immature female rats. Hum Exp Toxicol, 32(2), 172-185. https://doi.org/10.1177/ 0960327112462729

Wong, L. K., Dru, J., Lin, L. S., \& Knapp, J. (1983). Metabolism of 7,12-dimethylbenz[a]anthracene by Cunninghamella elegans. Appl Environ Microbiol, 46(5), 1239-1242.

Wu, W. S. (2006). The signaling mechanism of ROS in tumor progression. Cancer Metastasis Rev, 25(4), 695-705. https://doi.org/10.1007/s10555-006-9037-8

Xie, W., \& Du, L. (2011). Diabetes is an inflammatory disease: Evidence from traditional Chinese medicines. Diabetes Obes Metab, 13(4), 289-301. https://doi.org/10.1111/j.1463-1326.2010.01336.x

Yao, J. K., Leonard, S., \& Reddy, R. (2006). Altered glutathione redox state in schizophrenia. Dis Markers, 22(1-2), 83-93. https://doi.org/10.1155/2006/248387

Yeh, C. C., Hou, M. F., Tsai, S. M., Lin, S. K., Hsiao, J. K., Huang, J. C., ... Tsai, L. Y. (2005). Superoxide anion radical, lipid peroxides and antioxidant status in the blood of patients with breast cancer. Clin Chim Acta, 361(1-2), 104-111. https://doi.org/10.1016/j.ccen.2005.05.002

Yeh, C. C., Hou, M. F., Wu, S. H., Tsai, S. M., Lin, S. K., Hou, L. A., ... Tsai, L. Y. (2006). A study of glutathione status in the blood and tissues of patients with breast cancer. Cell Biochem Funct, 24(6), 555-559. https://doi.org/10.1002/cbf.1275

Yunbo, L., Shicui, Q., Dalin, D., Zhiqiang, W., Fei, G., \& Qian, L. (2002). Effect of pueraria lobata (willd.) ohwi (plo) on the immune function of mice. China Journal of Modern Medicine, 12(15), 62-63.

Zarzynska, J. M. (2014). Two faces of TGF-betal in breast cancer. Mediators Inflamm, 2014, 141747. https://doi.org/10.1155/2014/141747

Zhang, S., Chen, S., Shen, Y., Yang, D., Liu, X., Sun-Chi, A. C., \& Xu, H. (2006). Puerarin induces angiogenesis in myocardium of rat with myocardial infarction. Biol Pharm Bull, 29(5), 945-950. https://doi.org/10.1248/ Bpb.29.945

Zhang, W., Liu, C. Q., Wang, P. W., Sun, S. Y., Su, W. J., Zhang, H. J., ... Yang, S. Y. (2010). Puerarin improves insulin resistance and modulates adipokine expression in rats fed a high-fat diet. Eur J Pharmacol, 649(1-3), 398-402. https://doi.org/10.1016/j.ejphar.2010.09.054

Zhu, X., Wang, K., Zhang, K., Lin, X., Zhu, L., \& Zhou, F. (2015). Puerarin Protects Human Neuroblastoma SH-SY5Y Cells against Glutamate-Induced Oxidative Stress and Mitochondrial Dysfunction. J Biochem Mol Toxicol, 30(1), 22-28. https://doi.org/10.1002/jbt.21736

\section{Copyrights}

Copyright for this article is retained by the author(s), with first publication rights granted to the journal.

This is an open-access article distributed under the terms and conditions of the Creative Commons Attribution license (http://creativecommons.org/licenses/by/4.0/). 